\title{
Reorientation to more health promotion in health services - a study of barriers and possibilities from the perspective of health professionals
}

This article was published in the following Dove Press journal:

Journal of Multidisciplinary Healthcare

25 November 2010

Number of times this article has been viewed

\section{Helene Johansson ${ }^{1,3}$ \\ Hans Stenlund' \\ Lena Lundström ${ }^{2}$ \\ Lars Weinehall'}

'Epidemiology and Global Health, Department of Public Health and Clinical Medicine, ${ }^{2}$ Medical Rehabilitation, Department of Community Medicine and Rehabilitation, Umeå University, Umeå, Sweden; ${ }^{3}$ Ersboda Health Care Centre, Umeå, Sweden
Correspondence: Helene Johansson Epidemiology and Global Health,

Department of Public Health and Clinical Medicine, Umeå University, SE-90I 85

Umeå, Sweden

Tel +46907853349

Fax +46907852769

Email helene.johansson@epiph.umu.se
Aim: The objective of this study is to analyze the commitment to a more health-promoting health service and to illuminate important barriers for having a health-promoting role in daily practice, among Swedish health care professionals.

Material and method: Out of a total of 3751 health professionals who are working daytime in clinical practice in the province of Västerbotten, 1810 were invited to participate in a survey. The health professionals represented eight different occupational groups: counselors, dieticians, midwives, nurses, occupational therapists, physical therapists, psychologists, and physicians. A questionnaire that operationalized perceptions found in a previous qualitative study was mailed to residential addresses of the participants.

Results: The majority believed that health services play a major role in long-term health development in the population and saw a need for health orientation as a strategy to provide more effective health care. Willingness to work more in health promotion and disease prevention was reported significantly more often by women than men, and by primary health care personnel compared to hospital personnel. Among the professional groups, psychologists, occupational therapists, and physiotherapists most frequently reported willingness. The most common barriers to health promotion roles in daily practice were reported to be heavy workload, lack of guidelines, and unclear objectives.

Conclusions: This study found strong support for reorientation of health services in the incorporation of a greater health promotion. A number of professions that are not usually associated with health promotion practices are knowledgeable and wish to focus more on health promotion and disease prevention. Management has a major role in creating opportunities for these professionals to participate in health promotion practices. Men and physicians reported less positive attitudes to a more health-promoting health service and often possess high positions of power. Therefore, they may play an important role in the process of change toward more health promotion in health services.

Keywords: health promotion, health care professionals, health service, attitudes, barriers

\section{Introduction}

The 1986 Ottawa Charter stressed reorienting health services to more health promotion as one of the five important developing action areas to more effectively contribute to population health. ${ }^{1}$ However, an international evaluation over the first 20 years revealed that this part of the strategy had the least successful implementation. ${ }^{2}$ There was still significant imbalance between treatment and care versus health promotion activities.

Based on the determinants of health, a new Swedish national public health strategy was adopted by the parliament (Riksdag) in 2003 and updated in 2008. ${ }^{3,4}$ One of the 11 objective domains called for more health promotion in health services. Even if 
Swedish public health has a long history, the health services have a long way to go before they sufficiently embrace the idea of health promotion. ${ }^{5}$

The implementation of a more health-oriented health service is a multifaceted and complex process. It requires changes in professional behaviors and working methods as well as changes in organizational cultures and structures. ${ }^{6}$ The outcome depends on the interaction among the innovation itself, the intended adopters, and the context. ${ }^{7}$ The intended adopters (ie, the health professionals) are those who will take the operational decision on whether to deliver the 'news' ${ }^{6}$ Accordingly, they play a key role in the implementation process. If the goal of 'more health promotion in health services' is compatible with the health professional's own values, norms, and perceived needs, the prospects of a successful implementation will increase. ${ }^{7}$

With the overall objective of developing strategies for more health promotion in health services, focus group discussions were carried out with representatives from seven professional groups working in Swedish hospitals and primary health care settings in 2004 and 2005. The majority of informants perceived their role in health promotion practices as meaningful and valuable, and expressed visions of developing the role. At the same time, they felt limited by existing values, structures, and resources. ${ }^{8,9}$ Since the qualitative study addressed health professionals as a group, thus generating a spectrum of views and perceptions, the question was raised as to whether and to what extent the different views and approaches are represented in different professional groups. Therefore, the perceptions generated by the qualitative study resulted in formulation of questions. These questions were then used in a survey addressed to health workers in various categories.

This article reports findings from this specific study, analyzes the commitment to greater health promotion in health services, and illuminates important barriers for health promotion in daily practice.

\section{Methods}

\section{Setting}

The Swedish system offers universal access to health care. Health services are provided by 21 county councils/regions that are autonomous, publicly elected, and governed with taxation rights. This study was conducted within the Västerbotten county council. The county council administers two local hospitals, one university hospital, and 36 primary health care centers, and provides health and medical services for about 255,000 inhabitants.

\section{Participants}

There are a total of 3751 health professionals who work daytime in clinical practice and represent eight different occupational groups. All counselors $(n=141)$, dieticians $(n=29)$, midwives $(n=138)$, occupational therapists $(n=135)$, physical therapists $(n=224)$, psychologists $(n=114)$, and junior physicians $(n=317)$ were selected. As the groups of nurses and senior physicians were so large, a selection was made from a list. One of every five nurses $(n=409)$ and one of every two senior physicians $(n=303)$ were selected. Altogether 1810 were invited to participate in the study, of which $72 \%$ were women.

\section{Procedure}

The questionnaire used perceptions found in a previous qualitative study by Johansson et al $\mathrm{a}^{8,9}$ and was pilot-tested by 20 health professionals with varying educational and work experiences. The pilot testers were asked to answer the questionnaire and make their judgments on whether the items were comprehensible and relevant. Four of the pilot testers also participated in the focus group discussions.

The final version of the questionnaire was mailed with a postage-paid reply envelope to participants' residential addresses. Reminders were sent twice, and the last reminder included a copy of the questionnaire. The aim and content of the survey were described to participants in an introductory letter. They were informed that participation was voluntary and that confidentiality would be secured throughout the research process. Those who decided not to participate could avoid being sent reminders by returning the questionnaire unanswered. The study was approved by the local Ethics Committee at the Faculty of Medicine, Umeå University.

\section{Measures}

The questionnaire consisted of three parts. The first part assessed demographic variables including sex, date of birth, profession, years in profession, workplace (hospital, primary health care center, and others), and field of work (clinical work, research, and teaching).

The second part had seven items related to the health promotion and disease prevention role, four of which are reported in this article. As an introduction to this part of the questionnaire, the definitions of health promotion and disease prevention were given as follows: 'Health promotion is normally understood as a measure that is based on knowledge of what promotes good health, so-called healthy or protective factors. A mobilization of these factors leads both to increased resistance to illness and to faster recovery 
from illness. Disease prevention is based on knowledge of what causes ill-health, so-called risk factors. The aim is to prevent specific disease or injury. In health care it might be difficult to make a clear distinction between health promotion and disease prevention'.

To determine health professional's general attitudes toward more health promotion and disease prevention in health services, they were asked to rate a list of statements on a 4-point Likert scale ('strongly agree', 'partly agree', 'partly disagree', 'strongly disagree'). Answers were dichotomized into two categories: 'agree' and 'disagree'. Willingness to develop health promotion and disease prevention roles was measured with a single question: 'Do you work in a health promotion and disease prevention manner to the extent you wish?' (Yes/No, I want to work less/No, I want to work more). Respondents who marked 'No, I want to work more' were also asked to report barriers to health promotion/disease prevention roles in daily practice by selecting any number of 12 potential barriers. The response alternative 'other' had the opportunity to add comments.

The third part of the questionnaire contained four questions on the concept of health and will be reported elsewhere.

\section{Statistical analysis}

PASW Statistics 18 software (SPSS Inc., Chicago, IL) was used for descriptive analyses. Sampling weights for each professional group were used when estimating proportions (ie, number in target population/number of respondents). $\chi^{2}$ tests were used when comparing groups. $P$ values $<0.05$ were considered significant. Since weights were used when estimating proportions, Stata 10 software (Stata Corp, College Station, TX) was used to calculate $P$ values that accounted for weighting.

\section{Results}

\section{Response rate and respondents characteristics}

Twenty-four of the invited health professionals were later excluded for not meeting inclusion criteria (ie, they did not work during daytime in clinical practice). This left a sample of 1786 individuals. Of those, 688 individuals did not return the questionnaire (nonrespondents) and 135 returned the questionnaire unanswered (nonrespondents). Out of the remaining 963, 12 were excluded for not confirming inclusion criteria (nonrespondents). Consequently, the respondent group consisted of 951 individuals of whom 750 (79\%) were women.
The overall response rate was 53\%(951/1786) and varied between men (40\%) and women (59\%). Response rates also differed by professional groups: dieticians (66\%), occupational therapists and physiotherapists $(63 \%)$, psychologists $(62 \%)$, nurses and midwives (58\%), counselors (57\%), and physicians (40\%).

Table 1 shows the distribution of respondents by profession, sex, years in profession, workplace, and involvement in research/teaching. The mean age was 45 years (range 24-68 years) and mean years in profession were 16 (range 0-42 years). A majority (71\%) worked in hospitals, 25\% at primary health care centers, and $4 \%$ in other types of settings (eg, psychiatric treatment center, youth health clinic). In total, $20 \%$ of the respondents were involved in research and $22 \%$ in teaching. Ten percent were involved in both research and teaching.

\section{Attitudes toward more health promotion in health services}

Health professionals' attitudes toward more health promotion in health services are presented in Table 2. Ninety-six percent of respondents believed that health services play a major role in long-term health development within the population. Almost as many (93\%) also believed that health promotion and disease prevention are the responsibility of the entire health service, although $65 \%$ of men and $54 \%$ of women reported that it is primarily the responsibility of primary health care. Compared to hospital personnel (45\%), primary health care personnel $(69 \%)$ were more likely to report that health services should make prevention the priority rather than treatments. Among the eight different professional groups, the corresponding figures varied between 38\% (physicians) and 79\% (dieticians). Ninety-two percent agreed that health orientation, as a strategy, is necessary to provide more effective health care. Overall, men and physicians held less positive attitudes to more health promotion in health services.

\section{Willingness to do more health promotion and disease prevention}

Fifty percent of respondents reported that they work in health promotion and disease prevention to the extent they wish, $2 \%$ stated that they want to work less, and $45 \%$ were willing to focus more on health promotion and disease prevention (3\% missing responses). Figure 1 shows that willingness to do more health promotion and disease prevention was reported significantly more often by women $(50 \%)$ than men $(34 \%)$, and by primary health care personnel (59\%) compared to 
Table I Number of respondents in various categories

\begin{tabular}{|c|c|c|c|c|c|c|c|c|c|}
\hline & Counselor & Dietician & Midwife & Nurse & $\begin{array}{l}\text { Occup. } \\
\text { therapist }\end{array}$ & Physician & $\begin{array}{l}\text { Physio- } \\
\text { therapist }\end{array}$ & $\begin{array}{l}\text { Psycho- } \\
\text { logist }\end{array}$ & Total \\
\hline \multicolumn{10}{|l|}{$\operatorname{Sex}^{\mathrm{a}}$} \\
\hline Men & 6 & I & 0 & 34 & 4 & 113 & 28 & 14 & 200 \\
\hline Women & 73 & 18 & 78 & 203 & 81 & 130 & 112 & 55 & 750 \\
\hline \multicolumn{10}{|c|}{ Years in profession ${ }^{\mathrm{b}}$} \\
\hline $0-8$ & 16 & 7 & 17 & 67 & 16 & 92 & 32 & 29 & 276 \\
\hline $9-17$ & 6 & 6 & 23 & 61 & 44 & 57 & 61 & 15 & 273 \\
\hline $18-28$ & 28 & 5 & 19 & 57 & 19 & 55 & 28 & 15 & 226 \\
\hline $29-42$ & 27 & 1 & 19 & 47 & 5 & 35 & 16 & 10 & 160 \\
\hline \multicolumn{10}{|l|}{ Workplace } \\
\hline Hospital & 56 & 11 & 50 & 182 & 147 & 191 & 78 & 58 & 673 \\
\hline PHCC & 14 & 7 & 24 & 50 & 35 & 49 & 59 & 5 & 243 \\
\hline Other & 9 & 1 & I & 5 & 3 & 4 & 3 & 6 & 35 \\
\hline \multicolumn{10}{|c|}{ Field of work } \\
\hline \multicolumn{10}{|l|}{ Research } \\
\hline No & 9 & 11 & 71 & 212 & 76 & 143 & 124 & 54 & 761 \\
\hline Yes & 70 & 8 & 7 & 25 & 9 & 101 & 16 & 15 & 190 \\
\hline \multicolumn{10}{|l|}{ Teaching } \\
\hline No & 70 & 10 & 63 & 198 & 78 & 151 & 130 & 53 & 744 \\
\hline Yes & 9 & 9 & 15 & 39 & 7 & 92 & 20 & 16 & 207 \\
\hline Total & 79 & 19 & 78 & 237 & 85 & 244 & 140 & 69 & 951 \\
\hline
\end{tabular}

Notes: aPhysicians one missing value; 'Missing values $(n=16)$.

hospital personnel (43\%). Among the professional groups, figures varied between $70 \%$ (psychologists) and 38\% (counselors). Subgroup analyses found that female physiotherapists working at primary health care centers were most likely ( $81 \%$ ) and male counselors (22\%) and male physicians (28\%) working in hospitals were least likely to be willing to work more in health promotion and disease prevention (data not shown).

\section{Barriers for health promotion in practice}

On an average, respondents reported 3 out of 12 barriers (range 1-12). The distribution of reported barriers, with respect to sex, workplace, profession, years in profession, and involvement in research and teaching, are represented in Table 3. Figure 2 shows that the most commonly reported barrier was heavy workload (70\%), followed by lack of guidelines $(47 \%)$ and unclear objectives (40\%). Figure 3 reveals that heavy workload emerged as a greater problem for all professional groups who work at primary health care centers compared to those who work in hospitals. As a group, physicians (84\%) were most likely, and psychologists least likely (55\%), to report heavy workload as a barrier for health promotion in practice (Table 3 ).

In decreasing order of frequency, low priority from the management was the fourth barrier (31\%). Those involved in teaching were more likely to report this barrier (49\%) compared to those who were not teaching (27\%).
Limited competence was not shown to be a major problem for health promotion. With the exception of the physicians, all professional groups experienced their health promotion competence as not asked for/used in an optimal way as more important than limited competency (Table 3). For example, $70 \%$ of occupational therapists who work at primary health care centers stated that their health promotion competency was not asked for/used in an optimal way. Only $7 \%$ reported that their competency was limited (data not shown).

Table 3 shows that in addition to being a physician, reporting limited competency was significantly associated with few (0-8) years in the profession. Among physicians, hospital employees were more likely to report this barrier compared to those who work at primary health care centers (30\% versus $7 \%$, results not shown). Subgroup analyses of respondents with $0-8$ years of professional experience revealed that $65 \%$ of nurses working at primary health care centers and $44 \%$ of physicians working in hospitals reported limited competency (data not shown).

\section{Discussion}

\section{Limitations}

A complicating factor in a study like this is that there are different interpretations of what constitutes health promotion and the relationships between health promotion and disease prevention. Our previous qualitative study demonstrated that some informants (physicians) clearly distinguished between 


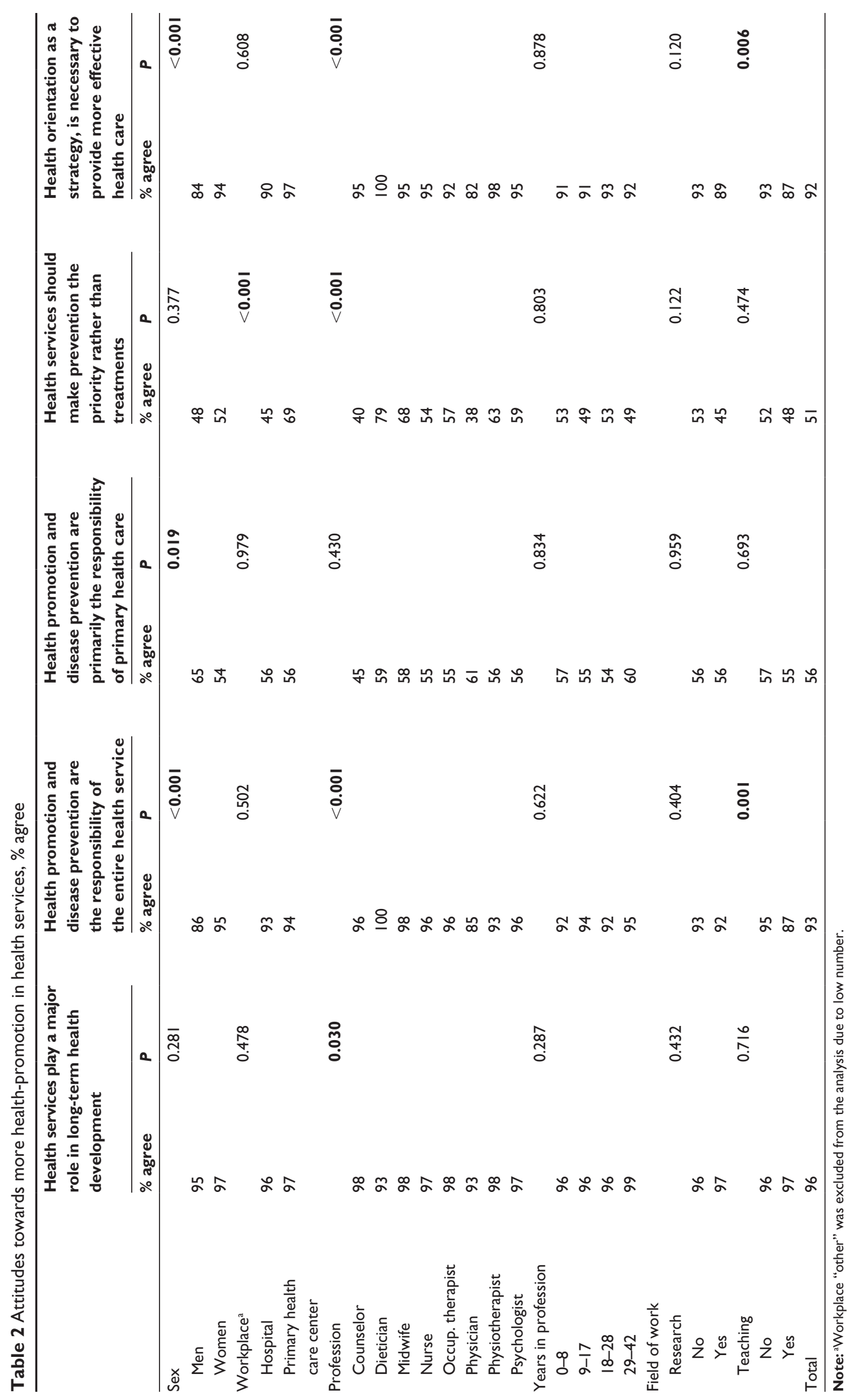




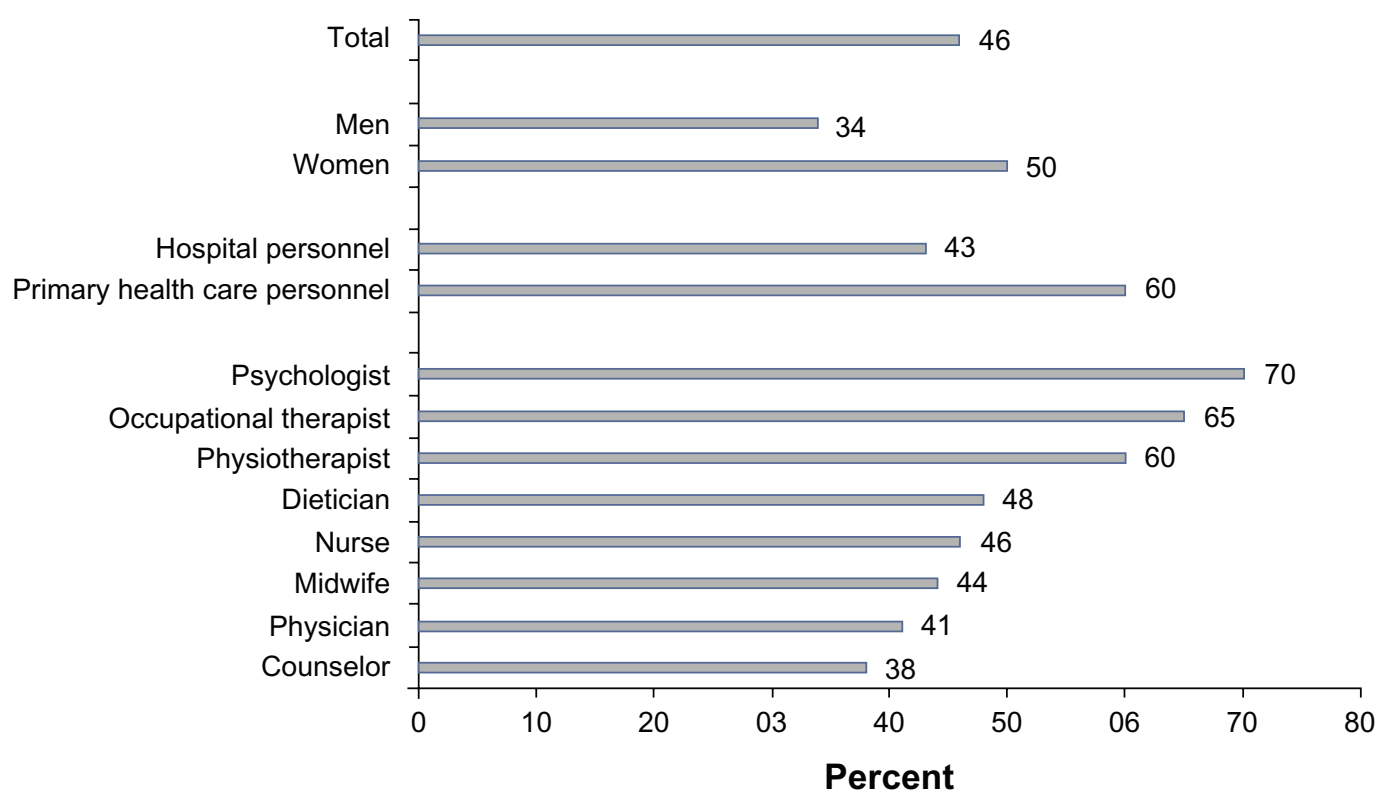

Figure I Reported willingness to focus more on health promotion and disease prevention, by sex, workplace, and profession $(P<0.00 \mathrm{I})$.

health promotion and disease prevention measures and were willing to take on prevention but not health promotion. ${ }^{8}$ The fact that the terms were used together in the questionnaire might have affected the response rate as well as the outcome. The aim with the question 'Do you work in a health promotion and disease prevention manner to the extent you wish' was intended to capture willingness to change. However, we are not able to tell the extent to which health professionals viewed health promotion as a part of their professional role or considered themselves to be doing health promotion and prevention in daily practice.

A number of reports show that studies of this nature usually do not have high response rates. A review by Cook et al showed that response rates to postal surveys of health care professionals were low and probably declining. ${ }^{10}$ Between 1996 and 2005, Cook et al found a mean of response rates of $56 \%$ with no significant difference between different types of surveys of health care professionals. In our study, the response rate was $53 \%$ and considerably lower among men and physicians. We have also been able to determine the response rates for some professional groups that work at primary health care centers ( $64 \%$ of counselors, $75 \%$ of nurses, $71 \%$ of occupational therapists, and $74 \%$ of physiotherapists). These show a higher response rate among primary health care personnel compared to hospital personnel. Besides the possibility of limited interest in health promotion, there are other possible explanations of nonresponse. First, we believe that, in addition to the 24 individuals who were excluded from the sample group because they were not clinically active, there were a number of nonrespondents because of long-term sick leave and leave of absence, cessation of employment, etc. These individuals should have been excluded from the sample group, and should not have received the survey. Second, the questionnaire was time-consuming and issues required special consideration, and this may have contributed to some decisions not to participate.

\section{Commitment to more health promotion in health services}

From a general viewpoint, health professionals are committed to the idea of more health promotion in health services. The vast majority believed that health services play a major role in long-term health development within the population and saw a need for health orientation as a strategy for providing a more effective health care. About half of the health professionals reported a willingness to develop their own health promotion and prevention role. A previous study among nurses showed that the nurses most interested in this development were those who already routinely practice health promotion. ${ }^{11}$

Not surprisingly, personnel working at primary health care centers were significantly more interested in developing health promotion and prevention than hospital personnel. This finding indicates a need to clarify the benefits of health promotion within the hospital settings. For example, Bensberg et al illustrate well the numerous opportunities to enhance health promotion in hospital emergency settings. ${ }^{12}$

The study also shows that women are significantly more interested in development of health promotion compared 
to men. This finding is in line with international research on physicians. Female physicians are found to have more favorable attitudes toward health promotion and to engage in more health promotion and prevention services and counseling activities. ${ }^{13-18}$ The gender effect is rarely discussed, but Henderson and Weisman suggest that female physicians may be more prevention-oriented and that gender differences in communication styles may facilitate different types of encounters. ${ }^{15}$ An assumption can be made that men, as a means of demonstrating masculinity, are less likely to adopt healthier beliefs and behaviors than women, ${ }^{19,20}$ and that personal health habits correlate with prevention-related counseling and screening practices. ${ }^{21}$ The social structuring of gender in society also affects the occupational choices of women and men in health care. ${ }^{22} \mathrm{~A}$ study among recent health care professional graduates found differences in both current and preferred working areas between male and female physiotherapists and nurses. ${ }^{23}$ The fact that such assignments are gender coded, ie, interpreted as feminine or masculine, also implies that they are given different value and status. ${ }^{24}$ The literature claims that men are escaping from caring and 'body-close' areas, and choosing to work in more acute and technical areas with higher status. ${ }^{22}$ The highest status or prestige is accorded to active, specialized, biomedical, and high-technological areas of medicine that are focused on organs in the upper body. ${ }^{25,26}$ How health promotion and prevention measures are ranked according to prestige has not been explored. Men and women may rank them differently. The conceptualization of health promotion as a term and what constitutes health promotion may also differ between men and women. Health promotion, compared to prevention, may be more strongly associated with long-term commitment, process, and communication, and thereby appeal more to women than men. Another possibility is that health promotion activities are more feminine-coded than prevention, and therefore given lower value and status.

The fact that psychologists, physiotherapists, and occupational therapists were most interested in role development is interesting given that health promotion practices usually are associated with (primary health care) nurses and physicians. However, health promotion is a multidisciplinary field and our result clearly shows that other professional groups perceive themselves as important providers of health promotion and disease prevention. Using psychologists as an example, Wahass argues that health promotion is a legitimate practice because psychologists are trained in the evaluation of human behaviors and play a major role in understanding how biological, behavioral, and social factors influence health and illness. ${ }^{27}$ Psychologists can help people modify their behaviors and lifestyles to prevent and recover from health problems. ${ }^{27,28}$ However, psychologists may have been too preoccupied with repairing damage rather than focusing on building strength and resilience. ${ }^{29}$

Counselors' expertise is psychosocial work. Within health care, counselors are responsible for the investigation, assessment, and treatment of psychosocial problems related to patients' state of ill health, care, and rehabilitation. ${ }^{30}$ Based on a salutogenic perspective and psychosocial knowledge, counselors make up a profession that contributes to a holistic view of humankind within the 'medical world' ${ }^{30}$ In this light, it is surprising that counselors, as contrasted to psychologists, were least likely to report willingness to work more in health promotion and prevention. Based on their competence and ideological perspectives, ie, equality, equity, security, and self-realization, ${ }^{31}$ it is clear that they have an important role to play as health promoters.

As a group, physicians were also less likely to report willingness to do more health promotion and prevention. It should be noted that it was male physicians who work in hospitals that lowered the mean value. Among these physicians, some are likely to be active in medical specialties with high prestige and status. Health care is gender-coded and hierarchical in its power relations between men and women, professional groups (with physicians at the very top), and between medical specialties. ${ }^{25}$ Therefore, a good question to ask is, if the male physicians who work in hospitals are less interested in further development of health promotion, what will be the consequences for setting priorities within health care systems and for the implementation of more health promotion in health services?

\section{Barriers for health promotion in practice}

The literature reveals that lack of time/heavy workload is a commonly experienced barrier for health promotion in practice. ${ }^{11,32-39}$ In our study, heavy workload emerged as the core constraint in all professional groups and was even more important for primary health care personnel than for hospital personnel. This is especially serious given that primary care is a particularly important player in health promotion because of its large contact area in the whole population.

Adequate time is an important element of individual capacity to practice health promotion (and in the personal and professional development that enhance such practices). ${ }^{40}$ This is true even if lack of time cannot always be blamed, and if there might always be reasons to suggest the need for workload reduction. Our previous qualitative study gave insight 
Table 3 Barriers for health promotion in practice, among those reporting willingness to focus more on health promotion and disease prevention

\begin{tabular}{|c|c|c|c|c|c|c|c|c|c|c|}
\hline & \multicolumn{2}{|c|}{$\begin{array}{l}\text { Limited } \\
\text { competence }\end{array}$} & \multicolumn{2}{|c|}{ Heavy workload } & \multicolumn{2}{|c|}{$\begin{array}{l}\text { Lack of managerial } \\
\text { support }\end{array}$} & \multicolumn{2}{|c|}{$\begin{array}{l}\text { No one listens } \\
\text { to my ideas }\end{array}$} & \multicolumn{2}{|c|}{$\begin{array}{l}\text { My competence is } \\
\text { not asked for/used }\end{array}$} \\
\hline & $\%$ & $P$ & $\%$ & $P$ & $\%$ & $P$ & $\%$ & $\boldsymbol{P}$ & $\%$ & $\boldsymbol{P}$ \\
\hline$\overline{\text { Sex }}$ & & 0.606 & & 0.437 & & 0.675 & & 0.308 & & 0.779 \\
\hline Men & 13 & & 74 & & 15 & & 8 & & 25 & \\
\hline Women & 16 & & 68 & & 13 & & 5 & & 22 & \\
\hline Workplace $^{a}$ & & 0.127 & & $<\mathbf{0 . 0 0 1}$ & & 0.318 & & 0.134 & & 0.224 \\
\hline Hospital & 18 & & 62 & & 12 & & 6 & & 21 & \\
\hline $\mathrm{PHCC}$ & II & & 87 & & 16 & & 3 & & 27 & \\
\hline Profession & & 0.022 & & 0.002 & & 0.394 & & 0.976 & & $<0.001$ \\
\hline Counselor & 14 & & 76 & & 28 & & 4 & & 22 & \\
\hline Dietician & 0 & & 79 & & 21 & & 0 & & 57 & \\
\hline Midwife & 12 & & 76 & & 20 & & 5 & & 29 & \\
\hline Nurse & 16 & & 64 & & 12 & & 5 & & 20 & \\
\hline Occup. therapist & 7 & & 74 & & 13 & & 6 & & 53 & \\
\hline Physician & 23 & & 84 & & II & & 6 & & 18 & \\
\hline Physiother & 5 & & 63 & & 16 & & 4 & & 37 & \\
\hline Psychologist & 4 & & 55 & & 8 & & 7 & & 17 & \\
\hline Years in profession & & $<0.001$ & & 0.711 & & 0.439 & & 0.191 & & 0.100 \\
\hline $0-8$ & 30 & & 72 & & 9 & & 2 & & 19 & \\
\hline $9-17$ & 8 & & 67 & & 12 & & 8 & & 32 & \\
\hline $18-28$ & 10 & & 72 & & 15 & & 7 & & 20 & \\
\hline $29-42$ & 7 & & 63 & & 19 & & 5 & & 17 & \\
\hline \multicolumn{11}{|l|}{ Field of work } \\
\hline Research & & 0.106 & & 0.648 & & 0.753 & & 0.278 & & 0.267 \\
\hline No & 17 & & 70 & & 13 & & 4 & & 22 & \\
\hline Yes & 10 & & 67 & & 14 & & 8 & & 29 & \\
\hline Teaching & & 0.267 & & 0.279 & & 0.219 & & 0.417 & & 0.255 \\
\hline No & 17 & & 68 & & 12 & & 5 & & 22 & \\
\hline Yes & II & & 75 & & 18 & & 7 & & 29 & \\
\hline Total & 16 & & 70 & & 13 & & 5 & & 23 & \\
\hline
\end{tabular}

into the ways in which lack of time impedes the delivery of health promotion services. ${ }^{9}$ Also in the present, quantitative study, several of the health professionals commented that they dealt with the 'time issue'. For example, they said that prioritization was given to those who are already ill, and that there was too little time with each patient and not enough time to focus on health promotion during emergency care. As long as no one demands access to health promotion efforts, curative care will be prioritized because the needs are more obvious and often require immediate action. Consequently, health promotion will be something that occurs infrequently and something extra that is added if the health professionals have time.

Lack of guidelines and unclear objectives were the second and third reasons given as barriers. A service with clear overall goal and tangible milestones increases the possibility of a shared vision of mission, and this in turn facilitates prioritization, coordination, and rationalization. ${ }^{41}$ In this manner, health promotion will not only become an expression of the individual employee's initiative and commitment.

Routines and programs promote the development of more structured and systematic health promotion. ${ }^{41}$ Evidence-based health promotion and disease prevention methods and strategies need to be applied more widely, as there are obvious opportunities for health services to prevent disease by supporting patients in changing unhealthy habits. To create a reasonably uniform practice among health care providers, the Swedish National Board of Health and Welfare is currently developing national guidelines for evidence-based methods that focus on preventive methods to influence tobacco use, hazardous use of alcohol, inadequate physical activity, and unhealthy eating habits. ${ }^{42}$

The fact that lack of competence did not appear as a major problem for health promotion activities could be questioned since effective health promotion requires a range of knowledge and skills. ${ }^{40,43}$ Dieticians, occupational 


\begin{tabular}{|c|c|c|c|c|c|c|c|c|c|c|c|c|c|}
\hline \multicolumn{2}{|c|}{$\begin{array}{l}\text { Low } \\
\text { decision-latitude }\end{array}$} & \multicolumn{2}{|c|}{$\begin{array}{l}\text { Unclear } \\
\text { objectives }\end{array}$} & \multicolumn{2}{|c|}{ Lack of guide lines } & \multicolumn{2}{|c|}{$\begin{array}{l}\text { Low priority from } \\
\text { the management }\end{array}$} & \multicolumn{2}{|c|}{$\begin{array}{l}\text { Lack of } \\
\text { reward-system }\end{array}$} & \multicolumn{2}{|c|}{$\begin{array}{l}\text { Lack of } \\
\text { co-operation }\end{array}$} & \multicolumn{2}{|c|}{ Other } \\
\hline$\%$ & $P$ & $\%$ & $P$ & $\%$ & $P$ & $\%$ & $P$ & $\%$ & $P$ & $\%$ & $P$ & $\%$ & $P$ \\
\hline & 0.843 & & 0.789 & & 0.476 & & 0.186 & & 0.886 & & 0.141 & & 0.505 \\
\hline 17 & & 38 & & 42 & & 39 & & 23 & & 30 & & 12 & \\
\hline \multirow[t]{2}{*}{18} & & 40 & & 48 & & 30 & & 22 & & 20 & & 10 & \\
\hline & 0.038 & & 0.858 & & 0.047 & & 0.872 & & 0.432 & & 0.583 & & 0.330 \\
\hline 21 & & 40 & & 51 & & 31 & & 24 & & 22 & & $\mathrm{II}$ & \\
\hline \multirow[t]{2}{*}{ II } & & 39 & & 38 & & 30 & & 19 & & 20 & & 8 & \\
\hline & 0.733 & & 0.110 & & 0.546 & & 0.201 & & 0.405 & & 0.697 & & 0.627 \\
\hline 22 & & 49 & & 49 & & 41 & & 31 & & 22 & & 10 & \\
\hline 14 & & 57 & & 57 & & 43 & & 21 & & 21 & & 21 & \\
\hline 20 & & 29 & & 48 & & 24 & & 32 & & 17 & & 5 & \\
\hline 16 & & 43 & & 46 & & 27 & & 21 & & 20 & & 10 & \\
\hline 13 & & 32 & & 39 & & 32 & & 19 & & 32 & & 10 & \\
\hline 22 & & 30 & & 46 & & 37 & & 26 & & 21 & & 9 & \\
\hline 16 & & 38 & & 60 & & 38 & & 20 & & 27 & & 12 & \\
\hline \multirow[t]{2}{*}{14} & & 49 & & $4 I$ & & 38 & & 10 & & 25 & & 20 & \\
\hline & 0.754 & & 0.414 & & 0.659 & & 0.782 & & 0.850 & & 0.278 & & 0.146 \\
\hline 15 & & 37 & & 47 & & 32 & & 22 & & 20 & & 9 & \\
\hline 21 & & 42 & & 48 & & 30 & & 21 & & 27 & & 17 & \\
\hline 16 & & 44 & & 52 & & 28 & & 26 & & 24 & & 8 & \\
\hline \multirow[t]{2}{*}{20} & & 29 & & 40 & & 37 & & 21 & & 12 & & 4 & \\
\hline & 0.758 & & 0.742 & & 0.401 & & 0.327 & & 0.373 & & 0.692 & & 0.388 \\
\hline 18 & & 40 & & 46 & & 30 & & 23 & & 21 & & 10 & \\
\hline \multirow[t]{2}{*}{16} & & 38 & & 52 & & 36 & & 18 & & 24 & & 13 & \\
\hline & 0.063 & & 0.537 & & 0.383 & & $<\mathbf{0 . 0 0 I}$ & & 0.286 & & 0.804 & & 0.989 \\
\hline 20 & & 40 & & 48 & & 27 & & 21 & & 21 & & 10 & \\
\hline 10 & & 36 & & 42 & & 49 & & 27 & & 23 & & 10 & \\
\hline 18 & & 40 & & 47 & & 31 & & 22 & & 22 & & 10 & \\
\hline
\end{tabular}

Note: "Workplace "other" was excluded from the analysis due to low number.

therapists, physiotherapists, and psychologists, based on their core professional knowledge, consider themselves to possess adequate health promotion competency. The physicians felt least skilled in dealing with health promotion and prevention issues. This finding might reflect that their work, compared to others, is more medically oriented. Lawrence argues that "physicians are by nature and training, problem-solvers, influenced by the diagnostic and therapeutic interventions made possible by the advances of biomedical science'. ${ }^{44}$ The literature suggests that physicians need more skills in health promotion interventions, lifestyle counseling, empowering communication, and in the task of motivation. ${ }^{9,12,32,33,45-47}$ However, our study found that in addition to creating structures that facilitate acquisition of further competencies, efforts to take advantage of the knowledge and skills that already exist among workers must be improved. The fact that limited competency was significantly associated with fewer years in profession indicates that education in health promotion needs to be reinforced in basic training programs.

\section{Conclusions and practical implications}

This study shows that there is strong support for the idea of implementation of more health promotion in health services. Half of the staff feel that health services should make prevention the priority rather than treatments. Although there is strong support for more health promotion, not all health professionals can be expected to have more health promotion and prevention as a personal work goal. There are several explanations for the fact that half of the health professionals did not report willingness to develop health promotion and prevention roles. Our study showed that on the group level, willingness was associated with gender, profession, and workplace (hospital or primary health care center). Why men and counselors are less interested needs to 


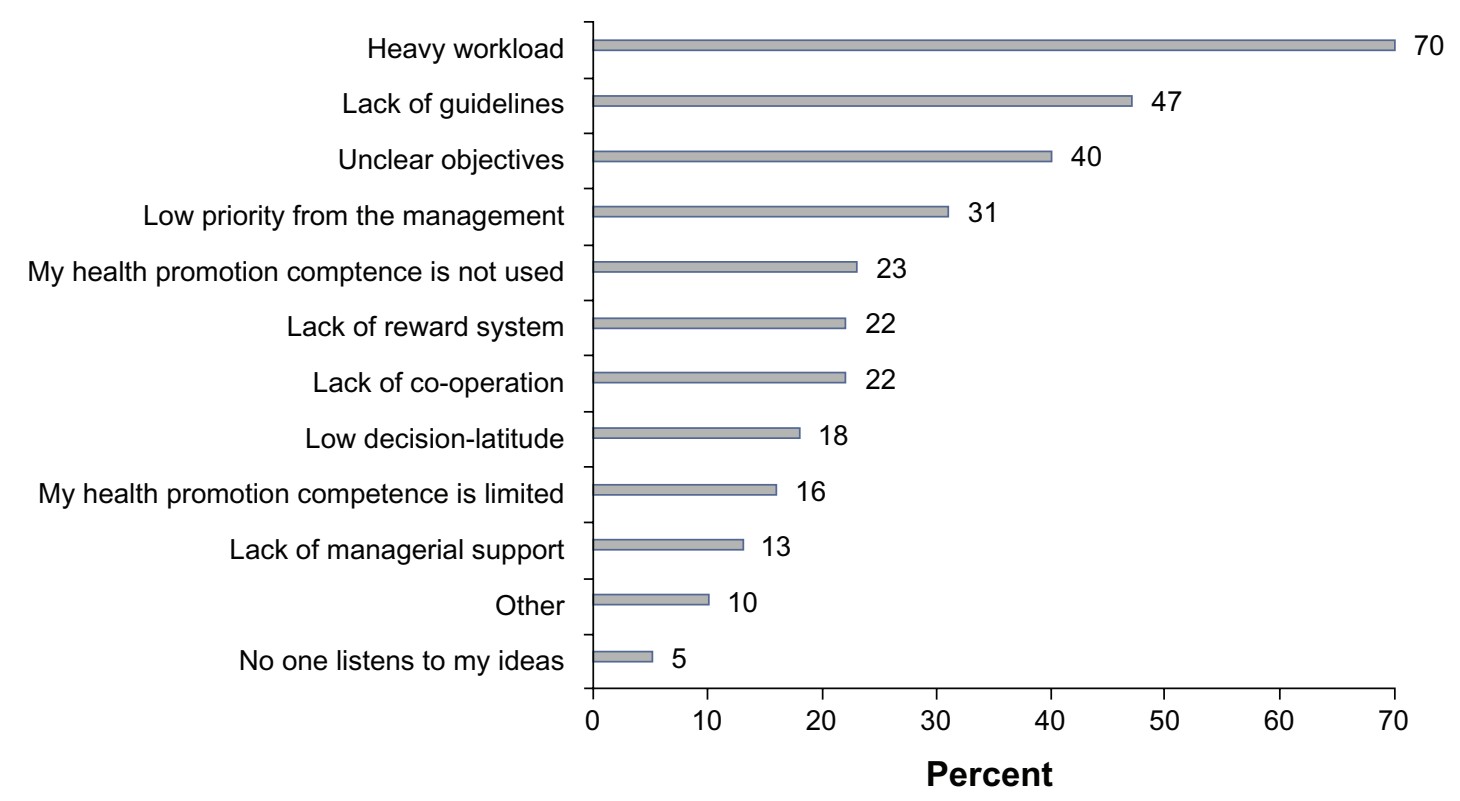

Figure 2 Barriers for health promotion in practice, presented in decreasing order of frequency.

be elucidated in future studies. On the individual level, traits, types of experiences, interests, and current tasks, interpretations of what may be incorporated into health promotion, and the ability to identify health promotion as part of their own professional role may be the explanations. A fear that they will not be able to develop the required new skills and behaviors may be another explanation.

An important leadership role is to provide direction, ie, to clarify the vision and strategy, and to create and seize interest and commitment for the work. ${ }^{48} \mathrm{~A}$ number of professions that are not usually associated with health promotion appear to have the knowledge and wish to focus more on health promotion and disease prevention. Management has a major role in taking advantage of the knowledge and the interest of such professionals, ie, psychologists, occupational therapists, and physical therapists, and to create opportunities for them to be part of a health promotion practice.

Men and physicians have less positive attitudes toward health promotion in health services. Male physicians who work in hospitals make up a large proportion of those who

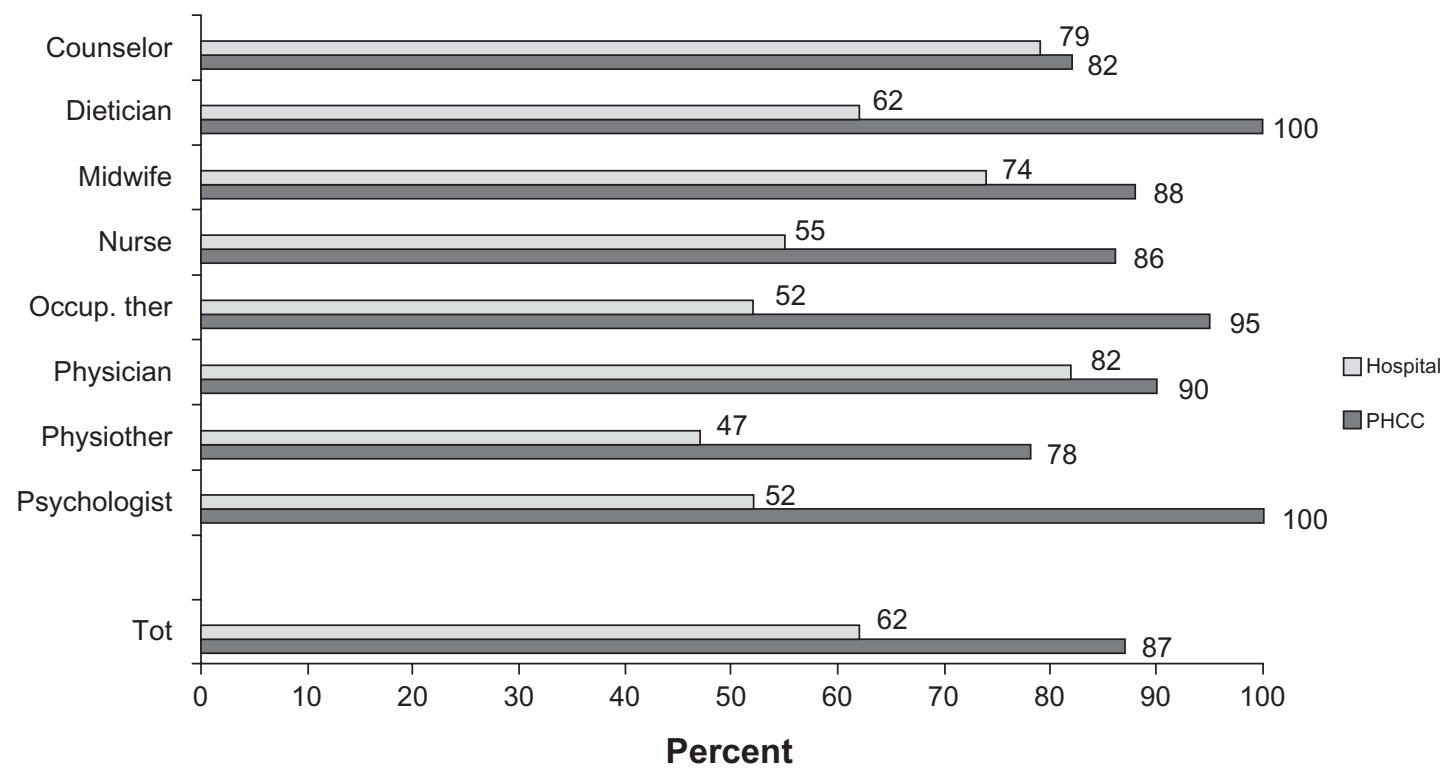

Figure 3 Percentages of respondents reporting heavy workload as a barrier for health promotion in practice, by profession and workplace (hospital and primary health care center) $(P<0.001)$. 
are not interested in developing their own health promotion roles. This group often possesses positions of power. It is, therefore, important to consider how they can be involved in the change process in an active and positive way.

In many respects, the various professions face similar barriers for performing health promotion in practice. In some cases, the barriers differ significantly, and they also differ between primary health care and hospital personnel. This means that health professionals have different opportunities for health promotion. Heavy workload emerged as the core constraint for all professional groups and was more important for primary health care compared to hospital personnel. This is a reality that cannot be ignored. Management support is critical for the availability of time and other resources required for health professionals to engage in health promotion. ${ }^{40}$ Hence, an important task at the managerial level is to provide support for staff in the prioritization of different actions and thereby direct the balance between health promotion/prevention and curative care. The fact that almost a quarter of health professionals claim that their knowledge is not used to advantage indicates that the potential for health promotion in health service is not optimally used.

Finally, it should be stressed that each person's energy, expertise, and innovation are needed to advance the businesses of health promotion. Through development of human systems and creation of conditions for human action and interaction, health promotion will move forward. By building trust, respect, and a good emotional climate, opportunities for learning, skill development, and regeneration will be created. ${ }^{49}$ In this way, health professionals will be supported in role development, dare to change their ways of thinking and their behaviors, and might be more willing to try new ways of working.

\section{Acknowledgments}

This study was undertaken within the Centre for Global Health at Umeå University, with support from FAS, the Swedish Council for Working Life and Social Research (grant no. 2006-1512). The study was also partially supported by the Swedish National Institute of Public Health and the County Council of Västerbotten, Sweden.

\section{Disclosure}

The authors report no conflicts of interest in this work.

\section{References}

1. World Health Organization. Ottawa Charter for Health Promotion. Copenhagen, Denmark: WHO Europe; 1986.

2. Wise M, Nutbeam D. Enabling the systems transformation: what progress has been made in re-orienting health services? Promot Educ. 2007; Suppl 2:23-27.
3. Government bill. Regeringens proposition 2002/03:35. Mål för folkhälsan [National Public Health Objectives]. Stockholm, Sweden: Socialdepartementet; 2002.

4. Government bill. Regeringens proposition 2007/08:110. En förnyad folkhälsopolitik [An Updated Public Health Policy]. Stockholm, Sweden: Socialdepartementet; 2007.

5. Pettersson B. Transforming Ottawa charter health promotion concepts into Swedish public health policy. Promot Educ. 2007;14(4):244-249.

6. Fixsen DL, Naoom SF, Blase KA, Friedman RM, Wallace F. Implementation Research: A Synthesis of the Literature. Tampa FL: University of South Florida, Louis de la Parte Florida Mental Health Institute, The National Implementation Research Network (FMHI Publication \# 231); 2005.

7. Greenhalgh T, Robert G, MacFarlane F, Bate P, Kyriakidou O. Diffusion of innovations in service organizations: systematic review and recommendations. Milbank Q. 2004;82(4):581-629.

8. Johansson H, Weinehall L, Emmelin M. "It depends on what you mean"; a qualitative study of Swedish health professionals' views on health and health promotion. BMC Health Serv Res. 2009;9:191.

9. Johansson H, Weinehall L, Emmelin M. "If we only got a chance". Barriers to and possibilities for a more health-promoting health service. J Multidiscip Healthc. 2010;3:1-9.

10. Cook JV, Dickinson H, Eccles MP. Response rates in postal surveys of healthcare professionals between 1996 and 2005: an observational study. BMC Health Serv Res. 2009;9:160.

11. Thomson P, Kohli H. Health promotion training needs analysis: an integral role for clinical nurses in Lanarkshire, Scotland. J Adv Nurs. 1997;26(3):507-514.

12. Bensberg M, Kennedy M, Bennetts S. Identifying the opportunities for health promoting emergency departments. Accid Emerg Nurs. 2003;11(3):173-181.

13. Bertakis KD, Helms LJ, Callahan EJ, Azari R, Robbins JA. The influence of gender on physician practice style. Med Care. 1995;33(4):407-416.

14. Frank E, Harvey LK. Prevention advice rates of women and men physicians. Arch Fam Med. 1996;5(4):215-219.

15. Henderson JT, Weisman CS. Physician gender effects on preventive screening and counseling. An analysis of male and female patients' health care experiences. Med Care. 2001;39(12):1281-1292.

16. Bertakis KD, Franks P, Azari R. Effects of physician gender on patient satisfaction. J Am Med Womens Assoc. 2003;58(2):69-75.

17. Rondeau KV, Francescutti LH, Cummings GE. Health promoting attitudes and behaviors of emergency physicians. Exploring gender differences. J Health Organ Manag. 2006;20(4):269-284.

18. Ramirez AG, Wildes KA, Nápoles-Springer A, Pérez-Stable E, Talavera G, Rios E. Gender differences in general and cancer-specific prevention. Attitudes and practices. J Cancer Educ. 2009;24(2):85-93.

19. Courtney WH. Engendering health: a social constructionist examination of men's health beliefs and behaviors. Psychol Men Masc. 2000; $1(1): 4-15$.

20. Courtney WH. Constructions of masculinity and their influence on men's well-being: a theory of gender and health. Soc Sci Med. 2000; 50(10):1385-1401.

21. Frank E, Rothenberg R, Lewis C, Belodoff BF. Correlates of physicians' prevention-related practices. Findings from the women physicians' health study. Arch Fam Med. 2000;9(4):359-367.

22. Jornfeldt I. Vårdvetenskap ur ett genusperspektiv [Caring sciences from a gender perspective]. In: Strömberg H, Eriksson H, editors. Genusperspektiv på vård och omvårdnad [Gender Perspectives on Health Care and Nursing]. Lund, Sweden: Studentlitteratur; 2006: 25-38.

23. Enberg B, Stenlund H, Sundelin G, Öhman A. Work satisfaction, career preferences and unpaid household work among recently graduated health-care professionals - a gender perspective. Scand J Caring Sci. 2007;21(2):169-177.

24. Öhman A. Genusperspektiv på vårdvetenskap [Gender Perspectives on Caring Sciences]. Stockholm, Sweden: Högskoleverket; 2009. 
25. Norredam M, Album D. Prestige and its significance for medical specialties and diseases. Scand J Public Health. 2007;35(6): 655-661.

26. Album D, Westin S. Do diseases have a prestige hierarchy? A survey among physicians and medical students. Soc Sci Med. 2008;66(1): 182-188.

27. Wahass SH. The role of psychologists in health care delivery. J Saudi Soc Fam Commun Med. 2005;12(2):1-8.

28. Russell-Mayhew S. Key concepts from health promotion evaluations: what psychology needs to know. Int J Adv Couns. 2004;28(2): 167-182.

29. Mcloughlin CS, Kubick JR Jr. Wellness promotion as a life-long endeavor: promoting and developing life competencies from childhood. Psychol Sch. 2006;41(1):131-141.

30. Lundin A, Benkel I, de Neergard G, Johansson B-M, Öhrling C. Kurator inom hälso- och sjukvård [Counselors (Social-Workers) in Health Care]. Lund, Sweden: Studentlitteratur; 2009.

31. Akademikerförbundet SSRs etikråd. Yrkesetiska riktlinjer för socionomer [Ethical guide-lines for social workers]. Available from: http://www. ifsw.org/cm_data/Sweden_ethics_swe.pdf. Accessed 2010 Sept 01

32. Herbert CP. Clinical health promotion and family physicians: a Canadian perspective. Pat Educ Couns. 1995;25(3):277-282.

33. Cornuz J, Ghali WA, di Carlantonio D, Pecoud A, Paccaud F. Physicians' attitudes towards prevention: importance of interventionspecific barriers and physicians' health habits. Fam Pract. 2000;17(6): 535-540.

34. Abramson S, Stein J, Schaufele M, Frates E, Rogan S. Personal exercise habits and counseling practices of primary care physicians: a national survey. Clin J Sport Med. 2000;10(1):40-48.

35. Whitehead D. The European health promoting hospitals project: how far on? Health Promot Int. 2004;19(2):259-267.

36. Broton C, Björkelund C, Bule M, et al. Prevention and health promotion in clinical practice: the views of general practitioners in Europe. Prev Med. 2005;40(5):595-601.

37. Jacobsen ET, Rasmussen SR, Christensen M, Engberg M, Lauritzen T. Perspectives on lifestyle intervention: the views of general practitioners who have taken part in a health promotion study. Scand J Public Health. 2005;33(1):4-10.
38. Robinsson KL, Driedger MS, Elliott SJ, Eyles J. Understanding facilitators of and barriers to health promotion practice. Health Promot Pract. 2006;7(4):467-476.

39. Casey D. Nurse's perceptions, understanding and experiences of health promotion. J Clin Nurs. 2007;16(6):1039-1049.

40. McLean S, Feather J, Butler-Jones D. Building Health Promoting Capacity: Action for Learning, Learning from Action. Vancouver, Canada: UBC Press; 2005.

41. National Institute of Public Health. Towards a More Health-Promoting Health Service. Summary of Study Material, Government Bills, Parliamentary Decisions, Draft Indicators and Examples of Application. Stockholm, Sweden: Swedish National Institute of Public Health; 2006:30.

42. Socialstyrelsen. Preliminär version: Nationella riktlinjer för sjukdomsförebyggande metoder. 2009. http://www.socialstyrelsen.se/ riktlinjer/nationellariktlinjer/sjukdomsforebyggandemetoder. Accessed 2010 Nov 1.

43. Irvine F. Exploring district nursing competencies in health promotion: the use of the Delphi technique. J Clin Nurs. 2005;14(8):965-975.

44. Lawrence RS. The role of physicians in promoting health [Commentary]. Health Aff. 1990;9(2):122-132.

45. Steptoe A, Dohert S, Kendrick T, Rink E, Hilton S. Attitudes to cardiovascular health promotion among GPs and practice nurses. Fam Pract. 1999;16(2):158-163.

46. Ghaith Al-Kuwari M. Health promotion practice among primary care physicians in Qatar. Middle East J Fam Med. 2008;7(1):18-22.

47. Moshki M, Ghahramani M, Shokravi FA. Impact of medical students' perceptions on health promotion: implications of healthy people 2010 . Eur J Sci Res. 2009;29(1):29-35.

48. Jacobsen DI, Thorsvik J. Hur moderna organisationer fungerar [How Modern Organizations Operate]. Lund, Sweden: Studentlitteratur; 2002 .

49. Södergren B. Kan en god arbetsmiljö främja energi, kompetens och innovationskraft? [Could a good working environment promote energy, skills and innovation?] In: God arbetsmiljö - en framgångsfaktor [A Good Working Environment-A Success Factor]. Statens offentliga utredningar SOU 2009:47. Stockholm (Sweden): Arbetsmiljöpolitiska kunskapsrådet; 2009:67-78.
Journal of Multidisciplinary Healthcare

\section{Publish your work in this journal}

The Journal of Multidisciplinary Healthcare is an international, peerreviewed open-access journal that aims to represent and publish research in healthcare areas delivered by practitioners of different disciplines. This includes studies and reviews conducted by multidisciplinary teams as well as research which evaluates the results or conduct of such teams or

\section{Dovepress}

healthcare processes in general. The journal covers a wide range of areas and welcomes submission from practitioners at all levels, from all over the world. The manuscript management system is completely online and includes a very quick and fair peer-review system. Visit http://www.dovepress.com/testimonials.php to read real quotes from published authors. 